10,06

\title{
Структура и динамика решетки двухслойных гетероструктур титаната бария-стронция и слоистого титаната висмута разной толщины на подложке оксида магния
}

\author{
(C) А.С. Анохин, Ю.И. Головко, В.М. Мухортов, Д.В. Стрюков \\ Федеральный исследовательский центр, Южный научный центр РАН (ЮНЦ РАН), \\ Ростов-на-Дону, Россия \\ E-mail: mukhortov1944@mail.ru
}

Поступила в Редакцию 23 мая 2019 г.

В окончательной редакции 17 июня 2019 г.

Принята к публикации 17 июня 2019 г.

Приведены результаты исследования структуры и динамики решетки монокристаллических пленок $\mathrm{Bi}_{4} \mathrm{Ti}_{3} \mathrm{O}_{12}$ толщиной от 4 до $430 \mathrm{~nm}$ на подложке $(001) \mathrm{MgO}$ с предварительно осажденным подслоем $\mathrm{Ba}_{0.4} \mathrm{Sr}_{0.6} \mathrm{TiO}_{3}(4 \mathrm{~nm})$. Двухслойные структуры получены при высокочастотном распылении керамических мишеней соответствующего состава. Рентгендифракционные исследования, выполненные при комнатной температуре, показали, что в такой гетероструктуре ось $c$ ячейки $\mathrm{Bi}_{4} \mathrm{Ti}_{3} \mathrm{O}_{12}$ перпендикулярна подложке, а направление [100] составляет угол $\pm 45^{\circ}$ с направлением [100] MgO. При толщине $\mathrm{Bi}_{4} \mathrm{Ti}_{3} \mathrm{O}_{12}$ до $\sim 40 \mathrm{~nm}$ элементарная ячейка пленки сжата в направлении нормали к плоскости подложки и растянута в плоскости сопряжения, а при больших толщинах происходит смена знака деформации. Обнаружены сдвиги частот фононных мод в пленке $\mathrm{Bi}_{4} \mathrm{Ti}_{3} \mathrm{O}_{12}$ и появление дополнительных пиков в спектрах комбинационного рассеяния света, что свидетельствует об увеличении степени моноклинного искажения кристаллической структуры пленок по сравнению со структурой кристалла.

Ключевые слова: сегнетоэлектрическая пленка, гетероструктуры, двумерные напряжения, динамики решетки.

DOI: 10.21883/FTT.2019.11.48425.489

\section{1. Введение}

Интересным сегнетоэлектрическим материалом для широкого применения в интегральной оптике является титанат висмута $\mathrm{Bi}_{4} \mathrm{Ti}_{3} \mathrm{O}_{12}[1]$, так как обладает большим электрооптическим коэффициентом, относительно невысокой диэлектрической проницаемостью и отсутствием эффектов усталости при переключении поляризации. Титанат висмута имеет слоистую перовскитную структуру, состоящую из чередующихся слоев $\left(\mathrm{Bi}_{2} \mathrm{O}_{2}\right)^{2+}$ и перовскитоподобных слоев $\left(\mathrm{Bi}_{2} \mathrm{Ti}_{3} \mathrm{O}_{10}\right)^{2-}$ вдоль оси $c$ элементарной ячейки. Имея параметры решетки в орторомбическом приближении $a=0.5448 \mathrm{~nm}$ и $b=0.5410 \mathrm{~nm}$, пленки титаната висмута эпитаксиально осаждаются на такие монокристаллические подложки как $\mathrm{SrTiO}_{3}$ и $\mathrm{LaAlO}_{3}$ [2-5]. Однако коэффициент преломления $\mathrm{SrTiO}_{3}(n=2.39)$ сравним по величине с коэффициентом преломления $\mathrm{Bi}_{4} \mathrm{Ti}_{3} \mathrm{O}_{12}(n=2.4 \sim 2.6)$, поэтому использование этих пленок затруднено в устройствах с оптическими волноводами. Желательно получить эпитаксиальные пленки $\mathrm{Bi}_{4} \mathrm{Ti}_{3} \mathrm{O}_{12}$ на монокристаллических подложках с более низким коэффициентом преломления, например $\mathrm{MgO}$, который имеет коэффициент преломления 1.74. Но получение эпитаксиальных пленок $\mathrm{Bi}_{4} \mathrm{Ti}_{3} \mathrm{O}_{12}$ на $\mathrm{MgO}$ затруднено из-за большого несоответствия и различной симметрии (моноклинная и кубическая) их решеток. Кроме того, отсутствует общепризнанная технология создания пленок $\mathrm{Bi}_{4} \mathrm{Ti}_{3} \mathrm{O}_{12}$ в монокристаллическом состоянии на диэлектрических подложках, и это сдерживает их применение в микроэлектронике. Для получения пленок $\mathrm{Bi}_{4} \mathrm{Ti}_{3} \mathrm{O}_{12}$ используются различные методы, такие как: из металлоорганических соединений (MOCVD) [6], импульсное лазерное осаждение (PLD) [7,8], молекулярно-лучевая эпитаксия (MBE) [9] и высокочастотное распыление [10]. Последний способ является одним из перспективных в силу простоты обеспечения состава исходной керамической мишени в пленке. Ранее нами были успешно получены при высокочастотном распылении керамических мишеней эпитаксиальные двухслойные гетероструктуры $\mathrm{Bi}_{4} \mathrm{Ti}_{3} \mathrm{O}_{12} /(\mathrm{Ba}, \mathrm{Sr}) \mathrm{TiO}_{3}$ на монокристаллах (001)Si [11]. Там же показано, что ориентацией кристаллических тонких пленок относительно подложки можно управлять варьированием состава подслоя $\mathrm{Ba}_{x} \mathrm{Sr}_{1-x} \mathrm{TiO}_{3}$. Например, использование предварительно осажденного слоя $\mathrm{Ba}_{0.4} \mathrm{Sr}_{0.6} \mathrm{TiO}_{3}$ толщиной $4 \mathrm{~nm}$ приводит к росту пленки $\mathrm{Bi}_{4} \mathrm{Ti}_{3} \mathrm{O}_{12}$ в монокристаллическом состоянии на подложке (001) Si. В настоящей работе приведены результаты по получению, исследованию структуры и динамики решетки монокристаллических пленок $\mathrm{Bi}_{4} \mathrm{Ti}_{3} \mathrm{O}_{12}$ различной толщины в двухслойной гетероструктуре с использованием в качестве подслоя $\mathrm{Ba}_{0.4} \mathrm{Sr}_{0.6} \mathrm{TiO}_{3}$ на подложке (001)MgO. Такая гетероструктура может послужить активной средой для интегральной оптики. 


\section{2. Экспериментальные результаты}

Для создания сегнетоэлектрических гетероструктур $\mathrm{Bi}_{4} \mathrm{Ti}_{3} \mathrm{O}_{12} /(\mathrm{Ba}, \mathrm{Sr}) \mathrm{TiO}_{3}$ на подложке $(001) \mathrm{MgO}$ использовалось высокочастотное катодное распыление керамических мишеней соответствующего состава при высоких давлениях кислорода ( 1 Torr) (установка „Плазма 50 С $Э$ “). Установлено, что рост $\mathrm{Bi}_{4} \mathrm{Ti}_{3} \mathrm{O}_{12}$ на $(001) \mathrm{MgO}$ при использовании подслоя $\mathrm{Ba}_{0.4} \mathrm{Sr}_{0.6} \mathrm{TiO}_{3}$ (толщиной 4-6 nm) происходит в монокристаллическом состоянии при температурах подложки более $400^{\circ} \mathrm{C}$. Слоевой механизм роста пленок был подтвержден исследованиями поверхности пленок методами электронной и атомно-силовой микроскопии (AFM Solver Pro кантилевер CSG11/Au). Следует заметить, что при осаждении $\mathrm{Bi}_{4} \mathrm{Ti}_{3} \mathrm{O}_{12}$ непосредственно на (100) $\mathrm{MgO}$ без подслоя происходит рост текстурированной пленки с направлением оси $c$ перпендикулярно подложке.

Рентгенодифрактометрические исследования проводились на рентгеновском дифрактометре ДРОН-4-07 $\left(\mathrm{Cu} K_{\alpha}\right.$-излучение, $\left.\lambda=0.154 \mathrm{~nm}\right)$ с гониометрической приставкой для исследования текстурных образцов. Это позволило использовать для получения структурных характеристик методы $\omega-2 \Theta$ съемки для симметричных отражений (отражающие плоскости параллельны поверхности образца) и методы $\omega-2 \Theta$ и $\varphi$-сканирование асимметричных отражений (отражающие плоскости непараллельны поверхности образца).

$\mathrm{Ha} \omega-2 \theta$ рентгенограммах пленок $\mathrm{Bi}_{4} \mathrm{Ti}_{3} \mathrm{O}_{12}$ толщиной от 4 до $430 \mathrm{~nm}$ присутствуют только (00L) отражения пленки и подложки (на рис. 1 приведены рентгенограммы для пленок толщиной 7 и $430 \mathrm{~nm}$ ). Это свидетельствует о том, что оси $c$ ячейки $\mathrm{Bi}_{4} \mathrm{Ti}_{3} \mathrm{O}_{12}$ и кубической ячейки подслоя $\mathrm{Ba}_{0.4} \mathrm{Sr}_{0.6} \mathrm{TiO}_{3}$ направлены перпендикулярно к подложке, оси $a$ и $b$ лежат в плоскости подложки. Плоскости решетки $b-c, c-a$ и $a-b$ соответственно обозначены в дальнейшем как (100), $(010)$ и (001) плоскости. Вертикальная разориентировка определялась по ширине на половине высоты (FWHM) кривой качания вокруг брэгговского угла для отражения (0014) $\mathrm{Bi}_{4} \mathrm{Ti}_{3} \mathrm{O}_{12}$ и составляет $\sim 0.82^{\circ}$. Так как угол $\beta$ моноклинной ячейки $\mathrm{Bi}_{4} \mathrm{Ti}_{3} \mathrm{O}_{12}$ незначительно отличается от $90^{\circ}$, то для описания структурных характеристик пленок $\mathrm{Bi}_{4} \mathrm{Ti}_{3} \mathrm{O}_{12}$ нами использовалось общепринятое орторомбическое приближение [12].

Взаимная ориентация осей $a$ и $b$ пленки и подложки в плоскости подложки определена из $\varphi$-сканирования (рис. 2) отражений (111ㅅ) пленки и отражений $(113) \mathrm{MgO}$. Из $\omega-2 \theta$ рентгенограмм и $\varphi$-сканирования пленок следует, что пленки $\mathrm{Bi}_{4} \mathrm{Ti}_{3} \mathrm{O}_{12}$ pacтут эпитаксиально на монокристаллической подложке $\mathrm{MgO}(001)$, причем (001) плоскости пленок $\mathrm{Bi}_{4} \mathrm{Ti}_{3} \mathrm{O}_{12}$ параллельны (001) MgO. Наличие четырех пиков при $\varphi$-сканировании отражений (111ㅡ) пленки $\mathrm{Bi}_{4} \mathrm{Ti}_{3} \mathrm{O}_{12}$, отстоящих друг от друга на $90^{\circ}$, свидетельствует о том, что в азимутальной плоскости присутствует два типа доменов: (1) $[110] \mathrm{Bi}_{4} \mathrm{Ti}_{3} \mathrm{O}_{12} / /[100] \mathrm{MgO}$

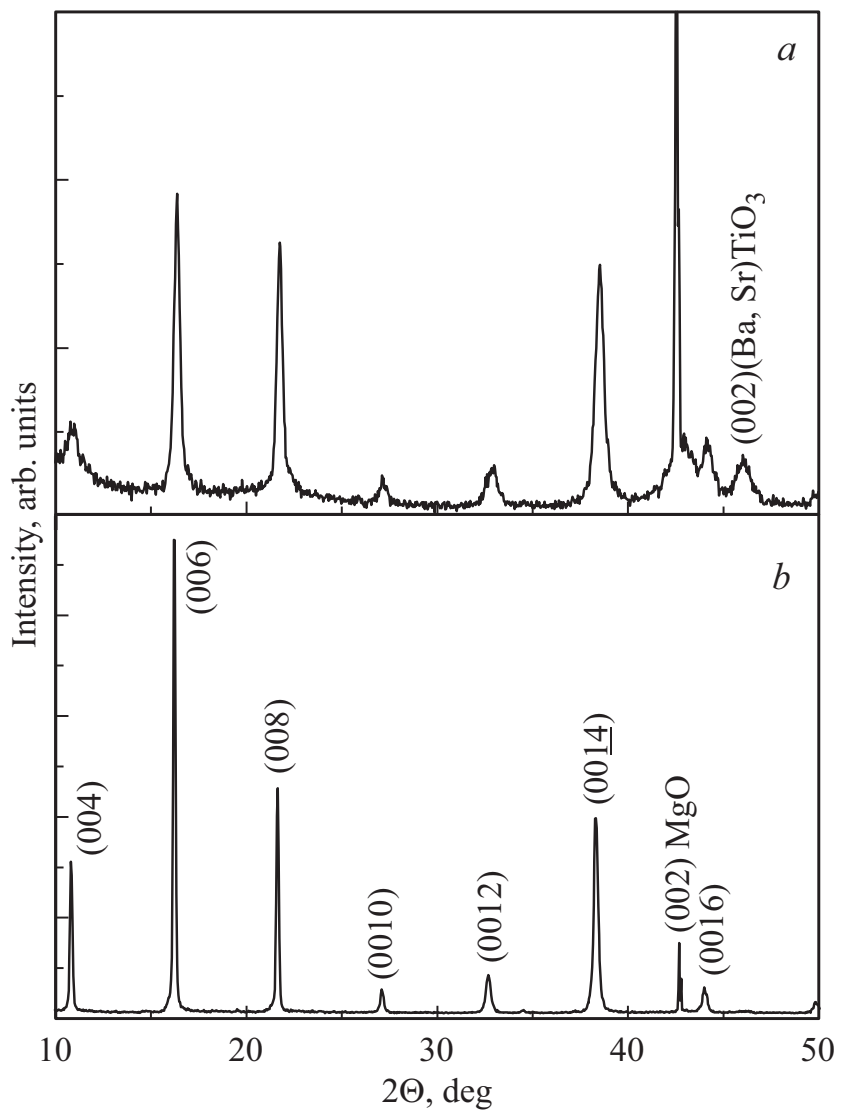

Рис. 1. $\omega-2 \theta$ рентгенограммы эпитаксиальных пленок $\mathrm{Bi}_{4} \mathrm{Ti}_{3} \mathrm{O}_{12}$. Толщина пленок: $a-7, b-430 \mathrm{~nm}$.

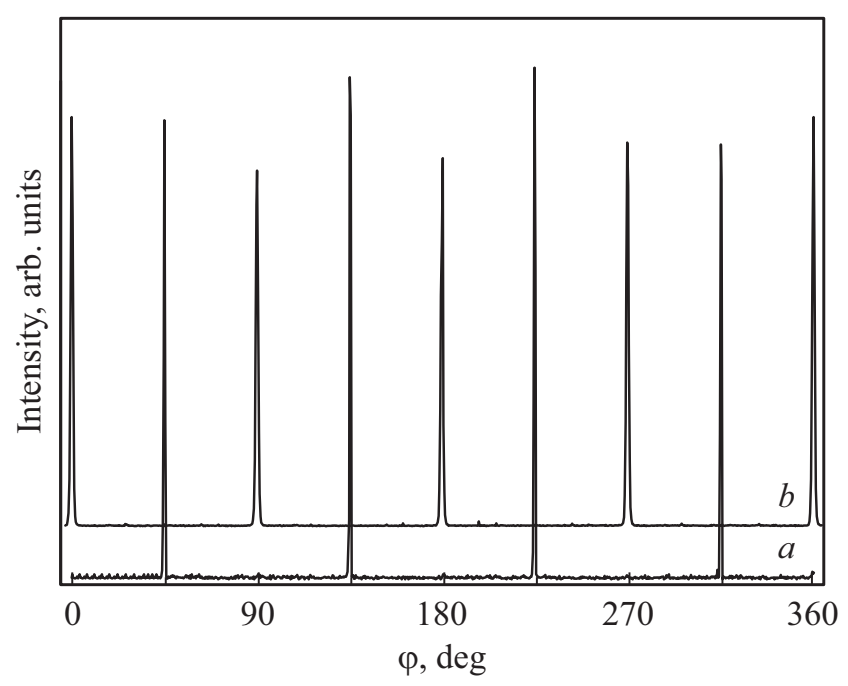

Рис. 2. $\varphi$-сканы отражений (113) $\mathrm{MgO}(a)$ и (1121) $\mathrm{Bi}_{4} \mathrm{Ti}_{3} \mathrm{O}_{12}(b)$, показывающие эпитаксиальные соотношения между $\mathrm{Bi}_{4} \mathrm{Ti}_{3} \mathrm{O}_{12}$ и $\mathrm{MgO}$.

и (2) $[110] \mathrm{Bi}_{4} \mathrm{Ti}_{3} \mathrm{O}_{12} / /[010] \mathrm{MgO}$, то есть направление [100] $\mathrm{Bi}_{4} \mathrm{Ti}_{3} \mathrm{O}_{12}$ составляет угол $\pm 45^{\circ}$ с направлением $[100] \mathrm{MgO}$. Эти ориентации связаны вращением на угол $90^{\circ}$ вокруг [001] оси МgO. Необходимо отметить, 
что возможны еще два типа ориентаций, которые возникают при вращении первого и второго типа доменов на $180^{\circ}$ вокруг [001] MgO. Появление этих четырех типов доменов является результатом различия между кристаллографическими симметриями (001) плоскости $\mathrm{Bi}_{4} \mathrm{Ti}_{3} \mathrm{O}_{12}$ и (001) поверхности $\mathrm{MgO}$. Ранее аналогичные результаты были получены для эпитаксиальных пленок $\mathrm{Bi}_{4} \mathrm{Ti}_{3} \mathrm{O}_{12}$, выращенных на (001) $\mathrm{SrTiO}_{3}$ подложках авторами работы [13]. Азимутальная разориентировка составляет $0.4^{\circ}$.

На рис. 3 показано изменение параметра решетки и неоднородной деформации пленки $\mathrm{Bi}_{4} \mathrm{Ti}_{3} \mathrm{O}_{12}$ на подложке $\mathrm{MgO}$ с подслоем при изменении толщины в перпендикулярном к плоскости подложки направлении. Из приведенной зависимости видно, что в области толщин до $\sim 40 \mathrm{~nm}$ параметр решетки $c$ меньше, чем параметр решетки объемного материала, что свидетельствует о том, что элементарная ячейка пленки сжата в направлении нормали к плоскости подложки и растянута в плоскости сопряжения. При толщине пленки больше $\sim 40 \mathrm{~nm}$ параметр решетки $c$ больше, чем параметр $c$ решетки объемного материала, что свидетельствует о том, что элементарная ячейка пленки растянута в направлении нормали к плоскости подложки и сжата в плоскости сопряжения. Неоднородная деформация уменьшается с увеличением толщины пленок, что свидетельствует о повышении структурного совершенства пленок. Факт получения дифракционных отражений, начиная с толщины пленки $4 \mathrm{~nm}$, высокая степень ориентации кристаллографических направлений пленки относительно подложки, малая ширина дифракционных отражений и небольшие значения неоднородных деформаций свидетельствует о высоком структурном совершенстве гетероструктуры $\mathrm{Bi}_{4} \mathrm{Ti}_{3} \mathrm{O}_{12} / \mathrm{Ba}_{0.4} \mathrm{Sr}_{0.6} \mathrm{TiO}_{3} / \mathrm{MgO}$.

Для уточнения симметрии элементарной ячейки пленки $\mathrm{Bi}_{4} \mathrm{Ti}_{3} \mathrm{O}_{12}$ проведены исследования динамики решетки пленок методом спектроскопии комбинационного рассеяния света (КРС). Для получения спектров КРС в диа-

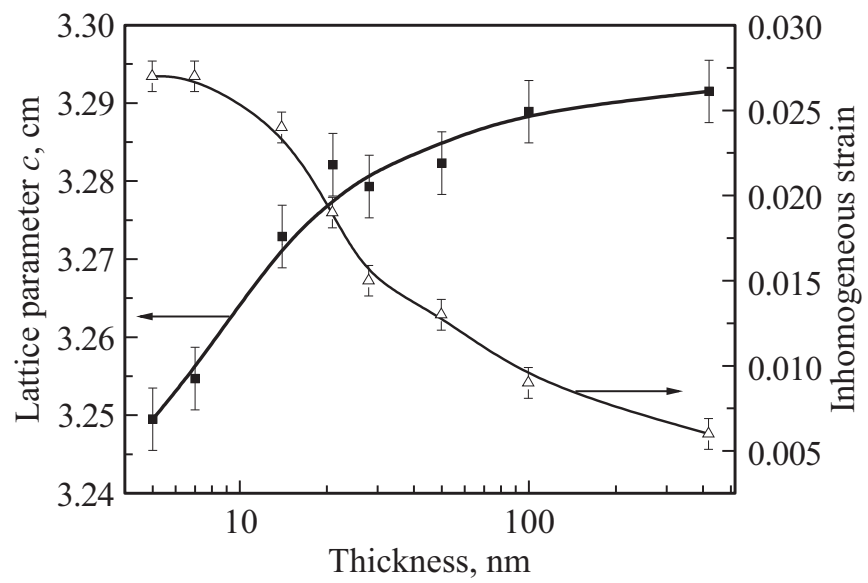

Рис. 3. Зависимость параметра решетки $c$ и неоднородных деформаций от толщины пленок $\mathrm{Bi}_{4} \mathrm{Ti}_{3} \mathrm{O}_{12}$, выращенных эпитаксиально на $\mathrm{MgO}(001)$ с подслоем $(\mathrm{Ba}, \mathrm{Sr}) \mathrm{TiO}_{3}$.
Положения линий при аппроксимации спектров пленок $\mathrm{Bi}_{4} \mathrm{Ti}_{3} \mathrm{O}_{12}$ набором лоренцианов

\begin{tabular}{|c|c|c|c|}
\hline \multirow{2}{*}{$\begin{array}{c}\text { № } \\
\text { линии }\end{array}$} & \multicolumn{3}{|c|}{ Положение линий $\left(\mathrm{cm}^{-1}\right)$} \\
\hline & $\begin{array}{c}\text { Пленка } 1 \\
\text { (толщина } 430 \mathrm{~nm} \text { ) }\end{array}$ & $\begin{array}{c}\text { Пленка } 2 \\
\text { (толщина } 50 \mathrm{~nm} \text { ) }\end{array}$ & $\begin{array}{l}\text { По данным } \\
\text { работы }[19]\end{array}$ \\
\hline$v 1$ & 31.0 & - & 27 \\
\hline$v 2$ & 45.5 & - & 42 \\
\hline$v 3$ & 63.6 & 71.3 & 62 \\
\hline$v^{*}$ & - & 81.5 & - \\
\hline$v 4$ & 88.1 & 89.6 & 87 \\
\hline$v 5$ & 101.5 & 105.0 & 102 \\
\hline$v 6$ & 118.6 & 116.0 & 117 \\
\hline$v 7$ & 142.1 & 142.0 & 147 \\
\hline$v 8$ & 194.1 & - & 187 \\
\hline$v 9$ & 228.3 & - & 227 \\
\hline$v 10$ & 270.6 & 275.0 & 270 \\
\hline$v 11$ & 334.6 & 333.0 & 332 \\
\hline$v 12$ & 411.4 & 411.0 & - \\
\hline$v 13$ & 450.8 & 450.0 & - \\
\hline$v 14$ & 490.4 & - & - \\
\hline$v 15$ & 544.3 & - & 537 \\
\hline$v 16$ & 572.2 & 571.0 & 558 \\
\hline$v 17$ & 615.3 & 615.0 & 613 \\
\hline$v 18$ & 695.8 & 700.0 & - \\
\hline$v 19$ & 803.5 & 803.0 & - \\
\hline$v 20$ & 850.0 & 850.0 & 851 \\
\hline
\end{tabular}

пазоне $10-1100 \mathrm{~cm}^{-1}$ использовалось поляризованное излучение аргонового лазера $(\lambda=514.5 \mathrm{~nm})$ и микроКРС спектрометр Renishaw inVia Reflex с NExT-фильтром, позволяющим записывать спектры в диапазоне от $10 \mathrm{~cm}^{-1}$. Спектр КРС регистрировался по схеме обратного рассеяния с помощью оптического микроскопа Leica $(\times 50$ объектив), диаметр лазерного пучка на образце составлял порядка $2 \mu \mathrm{m}$. Полученные спектры КРС были скорректированы на температурный фактор Бозе-Эйнштейна. На рис. 4, $a$ показан деполяризованный спектр КРС монокристаллической пленки $\mathrm{Bi}_{4} \mathrm{Ti}_{3} \mathrm{O}_{12}$ $(430 \mathrm{~nm})$, нанесенной на $\mathrm{MgO}$ с подслоем $\mathrm{Ba}_{0.4} \mathrm{Sr}_{0.6} \mathrm{TiO}_{3}$ $(4 \mathrm{~nm})$ - и его аппроксимация набором лоренцианов (рис. 4, b), параметры которых приведены в таблице. Представленный спектр КРС пленки согласуется с литературными данными для кристаллов (см. таблицу) того же состава [19].

Титанат висмута является фазой Ауривиллиуса с тремя октаэдрическими слоями в перовскитиподобным блоке. При этом в фононном спектре титаната висмута, согласно фактор-групповому анализу, следует ожидать 16 мод активных в КРС спектрах и 20 активных мод в спектрах инфракрасного поглощения (ИК): $\quad 6 A_{1 g}($ КРС $)+2 B_{1 g}($ КРС $)+8 E_{g}($ КРС $)+8 A_{2 u}($ ИК $)$ $+2 B_{2 u}(И К)+10 E_{u}(И К) \quad[15]$. Спектры КРС пленки $\mathrm{Bi}_{4} \mathrm{Ti}_{3} \mathrm{O}_{12}$ были записаны в геометрии обратного рассеяния, направление падающего и рассеянного излучения было перпендикулярно плоскости подложки. 


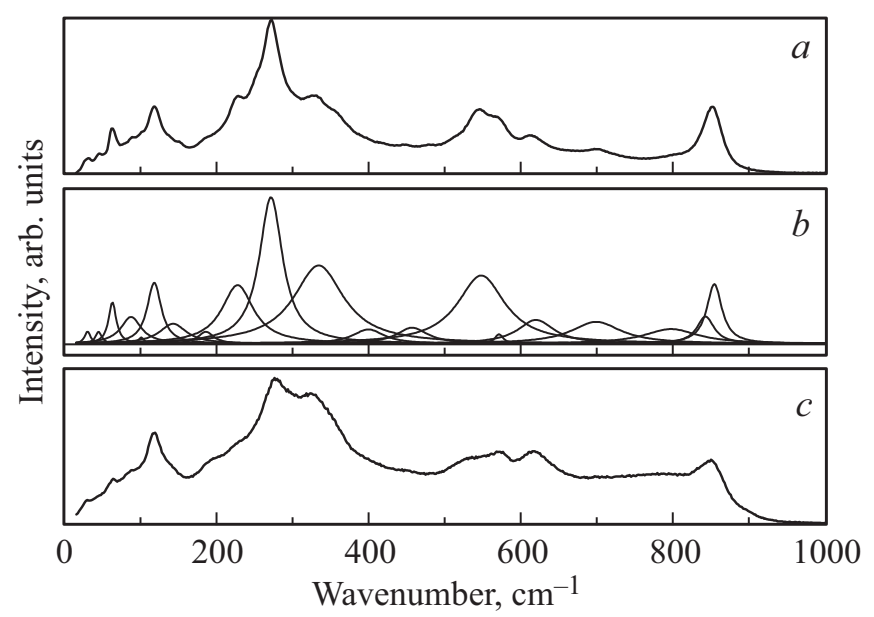

Рис. 4. $a-$ спектр КРС монокристаллической пленки $\mathrm{Bi}_{4} \mathrm{Ti}_{3} \mathrm{O}_{12}(430 \mathrm{~nm}), b-$ аппроксимация спектра КРС монокристаллической пленки $\mathrm{Bi}_{4} \mathrm{Ti}_{3} \mathrm{O}_{12}(430 \mathrm{~nm})$ набором лоренцианов (положение пиков приведены в таблице), $c$ - спектр КРС монокристаллической пленки $\mathrm{Bi}_{4} \mathrm{Ti}_{3} \mathrm{O}_{12}(50 \mathrm{~nm})$.

Фононный спектр гетероструктуры можно разбить на следующие области: низкочастотные моды с частотой менее $200 \mathrm{~cm}^{-1}(v 1-v 8)$ и высокочастотная область с частотой выше $200 \mathrm{~cm}^{-1}(v 9-v 20)$. Первая область относится к колебаниям ионов висмута $\mathrm{Bi}^{3+}$ как в $\left(\mathrm{Bi}_{2} \mathrm{O}_{2}\right)^{2+}$ слое, так и относительно кислородных октаэдров, а вторая область в спектре соответствует внутренним колебаниям $\mathrm{TiO}_{6}$ октаэдров. Самая низкочастотная $v 1$ мода является мягкой сегнетоэлектрической модой, соответствующей колебаниям висмута по отношению к октаэдрам $\mathrm{TiO}_{6}$ вдоль оси $a$ [16]. Поведение мягкой моды тесно связано с фазовыми переходами. Квадрат ее частоты линейно уменьшается при приближении к температуре Кюри, а в параэлектрической фазе мягкая мода перестает быть активной в спектрах КРС [14]. Повышение по сравнению с кристаллом частоты мягкой моды в пленке $\mathrm{Bi}_{4} \mathrm{Ti}_{3} \mathrm{O}_{12}$ (с 27 до $31 \mathrm{~cm}^{-1}$ ) может указывать на наличие деформации в данной гетероструктуре, вызванной действием подложки $\mathrm{MgO}[15,17]$. Линии в области частот $50-150 \mathrm{~cm}^{-1}(v 3-v 7)$ соответствуют колебаниям Ві относительно кислородных октаэдров.

Линия $v 3$ представляет собой жесткослоевую моду (rigid layer mode), которая относится к колебаниям $\mathrm{Bi}-\mathrm{O}$ связей в $\mathrm{Bi}_{2} \mathrm{O}_{2}$ слоях $[18,19]$. В пленке $\mathrm{Bi}_{4} \mathrm{Ti}_{3} \mathrm{O}_{12}$ $(430 \mathrm{~nm})$ частота $v 3$ моды равна $63.6 \mathrm{~cm}^{-1}$, что сопоставимо с частотами в кристаллах и керамиках титаната висмута (см. таблицу), и только в нанокристалле (размер грани $48 \mathrm{~nm}$ ) частота жесткослоевой моды уменьшается до $58 \mathrm{~cm}^{-1}$ из-за размерного эффекта [18]. Полосы $v 4-v 8$ соответствуют $\mathrm{Bi}-\mathrm{O}$ колебаниям внутри псевдоперовскитовых ячеек [19]. Фононные моды $v 9-v 20$, лежащие в области спектра выше $200 \mathrm{~cm}^{-1}$, относятся к колебаниям $\mathrm{Ti}^{4+}$ и $\mathrm{TiO}_{6}$ октаэдров. Линии $(v 9-v 11)$ в области частот $200-400 \mathrm{~cm}^{-1}$ отображают деформационные колебания $\mathrm{O}-\mathrm{Ti}-\mathrm{O}$ связей, а линии $(v 12-v 19)$ в области $500-800 \mathrm{~cm}^{-1}$ соответствуют валентным колебаниям. Моды $v 9$ и v10 является дисторсионными модами $\mathrm{TiO}_{6}$ октаэдра, мода $v 9$ является КРС-неактивной, когда симметрия $\mathrm{TiO}_{6}$ октаэдра $-\mathrm{O}_{h}$, но становится активной при искажении $\mathrm{TiO}_{6}$ октаэдра.

В пленках $\mathrm{Bi}_{4} \mathrm{Ti}_{3} \mathrm{O}_{12}$ повышается по сравнению с кристаллом частота колебания $v 15$ (до $544 \mathrm{~cm}^{-1}$ ), в то время как частота моды $v 20$, равная $850 \mathrm{~cm}^{-1}$, не изменяется. Такие же изменения наблюдались в спектре КРС порошка титаната висмута, допированного церием $\mathrm{Bi}_{4-x} \mathrm{Ce}_{x} \mathrm{Ti}_{3} \mathrm{O}_{12}$ [20], в спектре частота колебания $v 16$ увеличивалась с увеличением степени допирования Се. Данный эффект свидетельствует об изменении структурного искажения $\mathrm{TiO}_{6}$ октаэдров в пленке за счет деформации ячейки, обусловленной взаимодействием пленки с подложкой при эпитаксиальном росте. Высокочастотная линия $v 20$ с частотой $850 \mathrm{~cm}^{-1}$ соответствует полносимметричному валентному колебанию $\mathrm{O}-\mathrm{Ti}-\mathrm{O}$ связей внутри $\mathrm{TiO}_{6}$ октаэдров.

В пленке $\mathrm{Bi}_{4} \mathrm{Ti}_{3} \mathrm{O}_{12}$ толщиной $50 \mathrm{~nm}$ (рис. 4,c) происходит следующая трансформация КРС спектра. В низкочастотный области спектра в диапазоне $50-100 \mathrm{~cm}^{-1}$ появляются новые острые пики, аналогично низкотемпературным спектрах керамики $\mathrm{Bi}_{4} \mathrm{Ti}_{3} \mathrm{O}_{12}$ [14], что может указывать на снятие вырождения фононных мод и увеличение моноклинности в такой пленке. Частота пика $v 6$ уменьшается до $116 \mathrm{~cm}^{-1}$. Интенсивность пика $v 9\left(\sim 228 \mathrm{~cm}^{-1}\right)$ сильно уменьшается, и он сливается с крылом полосы $v 10$. В свою очередь, частота полосы $v 10$ увеличивается до $275 \mathrm{~cm}^{-1}$. Интенсивность линий $v 15-v 16$ значительно уменьшается, и становится равна интенсивности пика $v 17$. Интенсивность и частотное положение пика $v 17$ не изменяются. На частоте $890 \mathrm{~cm}^{-1}$ появляется пик, относящийся к спектру второго порядка подложки $\mathrm{MgO}$.

Таким образом, сдвиги частот фононных мод в пленке $\mathrm{Bi}_{4} \mathrm{Ti}_{3} \mathrm{O}_{12}$ и появление допонительных пиков в спектрах КРС свидетельствует о увеличении степени моноклинного искажения кристаллической структуры пленок по сравнению со структурой кристалла. При переходе в сегнетоэлектрическую фазу двукратно вырожденные $E_{g}$ фононы параэлектрической фазы должны расщепиться на $A^{\prime}$ и $A^{\prime \prime}$ компоненты, кроме того, все ИК-активные фононы должны стать активными в спектрах КРС моноклинной фазы титаната висмута, что должно приводить к увеличению числа линий в спектрах КРС. Однако в спектрах керамик и кристаллов $\mathrm{Bi}_{4} \mathrm{Ti}_{3} \mathrm{O}_{12}$ наблюдается намного меньшее число мод, чем это предсказано для моноклинной фазы, что может быть объяснено малыми моноклинными искажениями кристаллической структуры. В этом случае расщепление вырожденных мод мало и близкие по частотам моды сильно перекрываются, а часть линий, возникающих из ИК-активных мод параэлектрической фазы, не удается наблюдать из-за их малой интенсивности. Увеличение числа линий в низкотемпературных спектрах КРС керамики $\mathrm{Bi}_{4} \mathrm{Ti}_{3} \mathrm{O}_{12}$ [14], а также в спектрах пленок [15] и нанокристаллов [16] 
указывает на повышение степени моноклинности в таких образцах.

\section{3. Заключение}

Впервые, используя прерывистое высокочастотное распыление, показана возможность создания монокристаллических пленок $\mathrm{Bi}_{4} \mathrm{Ti}_{3} \mathrm{O}_{12}$ на $\mathrm{MgO}(001)$, используя подслой $\mathrm{Ba}_{0.4} \mathrm{Sr}_{0.6} \mathrm{TiO}_{3}$ толщиной $4 \mathrm{~nm}$. Высокое структурное совершенство подтверждено рентгенографическими исследованиями. Установлено, что в пленках $\mathrm{Bi}_{4} \mathrm{Ti}_{3} \mathrm{O}_{12}$ ориентация оси $c$ перпендикулярна подложке, а в азимутальной плоскости $[110] \mathrm{Bi}_{4} \mathrm{Ti}_{3} \mathrm{O}_{12} / /[100] \mathrm{MgO}$ и $[110] \mathrm{Bi}_{4} \mathrm{Ti}_{3} \mathrm{O}_{12} / /[010] \mathrm{MgO}$. Показано, что в гетероструктуре $\mathrm{Bi}_{4} \mathrm{Ti}_{3} \mathrm{O}_{12} / \mathrm{Ba}_{0.4} \mathrm{Sr}_{0.6} \mathrm{TiO}_{3} / \mathrm{MgO}(001)$ при изменении толщины пленок $\mathrm{Bi}_{4} \mathrm{Ti}_{3} \mathrm{O}_{12}$ наблюдается изменение внутренних деформационных полей. Это проявляется в наличии критической толщины $\sim 44.5 \mathrm{~nm}$, при которой растягивающие напряжения в плоскости пленки изменяются на сжимающие. Моноклинная симметрия элементарной ячейки пленки $\mathrm{Bi}_{4} \mathrm{Ti}_{3} \mathrm{O}_{12}$ подтверждена исследованиями динамики решетки пленок методом спектроскопии комбинационного рассеяния света.

\section{Финансирование}

Государственное задание по проекту № 0120-1354-247, грант РФФИ № 16-29-14013.

\section{Конфликт интересов}

Авторы заявляют, что у них нет конфликта интересов.

\section{Список литературы}

[1] C.D. Theis, J. Yeh, D.G. Schlom, M.E. Hawley, G.W. Brown, J.C. Jiang, X.Q. Pan. Appl. Phys. Lett. 72, 2817 (1998).

[2] G.W. Brown, M.E. Hawley, C.D. Theis, J. Yeh, D.G. Schlom. Thin Solid Films 357, 13 (1999).

[3] W. Jo, H-J. Cho, T.W. Noh, B.I. Kim, D-Y. Kim, Z.G. Khim, S. Kwun. Appl. Phys. Lett. 63, 2198 (1993).

[4] K. Hwang, Y. Park. J. Mater. Res. 16, 2519 (2001).

[5] W. Jo, G-C. Yi, T.W. Noh, D-K. Ko, Y.S. Cho, S-I. Kwun. Appl. Phys. Lett. 61, 1526 (1992).

[6] B.H. Park, B.S. Kang, S.D. Bu, T.W. Noh, J. Lee, W. Joe. Lett. Nature 401, 682 (1999).

[7] O. Khorkhordin, Chia-Pin Yeh, B. Kalkofen, E. Burte. J. Crystallization Proc. Technology 5, 49 (2015).

[8] D.H. Kuo, K.C. Chiang. Thin Solid Films 516, 5985 (2008).

[9] C.D. Theis, J. Yeh, D.G. Schlom, M.E. Hawley, G.W. Brown, J.C. Jiang, X.Q. Pan. Appl. Phys. Lett. 72, 2817 (1998).

[10] C.M. Bedoya-Hincapie, E.R. Parra, J.J. Olaya-Florez, J.E. Alfonso, F.J. Flores-Ruiz, F.J. Espinoza-Beltran. Ceram. Int. 40, 11831 (2014).

[11] А.С. Анохин, С.В. Бирюков, Ю.И. Головко, В.М. Мухортов. ФТТ 61, 278 (2019).

[12] Q. Zhou, B.J. Kennedy, C.J. Howard. Chem. Mater. 15, 5025 (2003).
[13] X.Q. Pan, J.C. Jiang, C.D. Theis, D.G. Schlom. Appl. Phys. Lett. 83, 2315 (2003).

[14] K. Liang, Y. Qi, C. Lu. J. Raman Spectrosc. 40, 2088 (2009).

[15] P.R. Graves, G. Hua, S. Myhra, J.G. Thompson. J. Solid State Chem. 114, 112 (1995).

[16] S. Kojima, S. Shimada. Phys. B Condens. Matter. 219-220, 617 (1996).

[17] M. Osada, M. Tada, M. Kakihana, Y. Noguchi, M. Miyayama. Mater. Sci. Eng. B Solid-State Mater. Adv. Technol. 120, 95 (2005).

[18] Y.L. Du, M.S. Zhang, Q. Chen, Z. Yin. Appl. Phys. A 76, 1099 (2003).

[19] A.V. Knyazev, M. Mączka, O.V. Krasheninnikova, M. Ptak, E.V. Syrov, M. Trzebiatowska-Gussowska. Mater. Chem. Phys. 204, 8 (2018).

[20] M.K. Jeon, Y.-I. Kim, S.-H. Nahm, S.I. Woo. J. Phys. D 39, 5080 (2006).

Редактор К.В. Емцев 